\section{DESDOBLADO DE DOLOR: ESTÉTICA DE LA ANESTESIA}

\author{
Francisco González Fernández \\ Universidad de Oviedo \\ ORCID iD: https://orcid.org/0000-0002-1391-6646 \\ frangon@uniovi.es
}

Cómo citar este artículo/Citation: González Fernández, F. (2018). Desdoblado de dolor: estética de la anestesia. Arbor, 194 (790): a482. https://doi.org/10.3989/arbor.2018.790n4007

Recibido: 25 marzo 2015. Aceptado: 25 agosto 2017.

RESUMEN: A lo largo del siglo XIX el tema literario del doble experimenta un cambio notable, tanto por el ínsólito incremento del número de relatos dedicados a este personaje como por la naturaleza siniestra que adquiere entonces. Entre los múltiples factores que favorecieron la aparición de este doppelgänger destacan los avances y descubrimientos que se produjeron en esos años en el campo de la medicina, especialmente en lo concerniente al dolor y a su posible supresión. La manifestación del sufrimiento produce en el paciente una sensación de despersonalización y disociación que lo lleva a identificar su sufrimiento con un "ello", como si fuera un antagonista, como si del dolor emergiera un doble. El descubrimiento de la anestesia hacia 1850 trajo consigo la reevaluación de la experiencia del dolor, que dejó de ser entonces considerado como inseparable de la vida. La capacidad para eliminar el sufrimiento propició su objetivación, y numerosos poetas y novelistas convirtieron la antigua y legendaria figura del doble en el receptáculo donde hicieron cristalizar sus efectos disociativos.

PALABRAS CLAVE: Dolor; doble; doppelgänger; anestesia; fantasmagoría; experimento.

\section{UNFOLDED WITH PAIN: THE AESTHETICS OF ANESTHESIA}

Copyright: (c) 2018 CSIC. Este es un artículo de acceso abierto distribuido bajo los términos de la licencia de uso y distribución Creative Commons Reconocimiento 4.0 Internacional (CC BY 4.0).

ABSTRACT: Throughout the $19^{\text {th }}$ century, the literary theme of the "double" underwent a significant change, due both to the remarkable increase in the number of narratives devoted to this theme, and to the sinister nature it adopted at that time. Amongst the multiple factors which favored the advent of this doppelgänger we highlight the advances and discoveries that were made in the field of medicine during those years, especially concerning pain and the possibility of suppressing it. Suffering provokes in the patient a feeling of depersonalization and dissociation which makes him associate his suffering with an "it", a sort of antagonist, as if a double emerges from the experience of pain itself. The discovery of anesthesia around 1850 brought about a reassessment of the experience of pain, which ceased to be regarded as inseparable from life. The capacity to suppress suffering facilitated its objectivization, and several poets and novelists turned the old and legendary figure of the double into a receptacle where its dissociative effects crystalized.

KEYWORDS: Pain; double; doppelgänger; anesthesia; phantasmagory; experiment. 
El doble es una sombra descosida. El doble acompaña al hombre desde la noche de los tiempos, custodia al individuo desde su nacimiento. Aunque su presencia recorre toda la historia de la literatura hay que esperar sin embargo a la época moderna para que llegue a constituirse en un auténtico tema literario. El siglo XIX supuso a este respecto un verdadero punto de inflexión, no solo por la inusitada proliferación de novelas, cuentos y relatos fantásticos protagonizados por un doble, sino sobre todo por la transformación que sufre entonces esta figura, que pasa de ser una sombra protectora o un personaje jocoso a convertirse en una aparición inquietante y a menudo siniestra. Teorías clásicas del doble que descansan sobre el temor a la muerte o a lo reprimido como la de Otto Rank o la de Sigmund Freud aportaron sin duda valiosas explicaciones de carácter general, pero no ayudaron demasiado a entender la fascinación que este tema había ejercido sobre los escritores modernos. El doble es sin duda una figura universal; no obstante, su enfermiza propagación en la literatura decimonónica parece haber respondido a una nueva visión de la realidad, a una nueva sensibilidad.

A partir de la revolución francesa se produjo una mutación radical en la naturaleza del individuo al dejar de ser el árbol genealógico el vector de la identidad (cf. Arnaud, 2006, p. 30), pero pronto se hizo evidente que este nuevo Yo desarraigado era tan escurridizo como la propia sombra. Simultáneamente, la concepción romántica del hombre, constantemente dividido entre la finitud de su Yo y la atracción hacia lo absoluto, no hizo más que encerrar al individuo en un laberinto de aporías en cuyo centro aguardaba la figura siniestra del doppelgänger. Ahora bien, ni la creciente autarquía del individuo moderno ni la extrema atención que prestaron al Yo los románticos permiten explicar por sí solos el éxito que alcanzaría el doble a lo largo del siglo XIX. Para poder entender el surgimiento de este tema literario es preciso asimismo considerar los avances y descubrimientos que fructificaron por esos años en el campo de la medicina y que ejercieron sobre la nueva configuración de la identidad una poderosa influencia. Como indica Yves Pélicier (1995, p. 124), el Romanticismo y el resto de los movimientos decimonónicos encontraron una importante provisión de temas literarios emparentados con el Doppelgänger en el mesmerismo, en el magnetismo animal, en el sonambulismo provocado, en la hipnosis y en la histeria cuyo estudio precisamente planteaba a todas luces el problema de la unidad del ser. El dolor, que se convierte entonces en el medio mediante el cual la medicina clínica investiga los senti- dos y la sensibilidad, será otro de los factores determinantes, como se verá, que explican el advenimiento, proliferación y mutación del doble en la imaginación literaria de esta época. El doble siniestro emerge también de los sueños de la medicina, de sus intentos de suprimir el dolor y el sufrimiento. Porque el doble se desprende del dolor, como si cobrara forma a través de su objetivación, como si fuera su propia imagen.

La manifestación del dolor comparte con el doble un rasgo esencial en el que no suele repararse a la hora de abordar este tema literario. El sufrimiento es sin duda la experiencia humana más individual e incomunicable. Salvo imperfectas e infructuosas metáforas (cuchillo, martillo, mordisco, garras, etc.), no hay palabras que puedan realmente transmitir lo que se siente al padecer un dolor físico. Confrontado a un acontecimiento indecible y radicalmente personal, el individuo doliente no solo permanece aislado de los demás, sino también de sí mismo, pues el dolor confiere al propio cuerpo una extrañeza absoluta y se convierte en una temible amenaza para la identidad del sujeto. David Le Breton recuerda a este respecto que al intentar expresar su dolor, numerosos pacientes acostumbran evocar la imagen de una entidad extraña que los desmantela desde dentro: "El dolor es un momento de la existencia en que se sella para el individuo la impresión de que su cuerpo es distinto de él. Una dualidad insuperable e intolerable lo encierra en una carne rebelde que lo constriñe a un sufrimiento del que él mismo es el propio crisol" (Le Breton, 2006 , p. 24). El dolor intenso provoca en quien lo sufre una sensación de despersonalización y de disociación: "El individuo se vive a sí mismo como una casa embrujada por la enfermedad o el dolor. De pronto no puede reconocer que forman cuerpo con él, que son suyos, los quiere del Otro, externos, como si hacer entrar el mal en sí fuera el signo de una abdicación ante la alteridad. Imagen ejemplar de la irrupción del ello, el dolor despersonaliza." (Le Breton, 2006, p. 25). De ahí que la experiencia del dolor sea vivida desde tiempos inmemoriales como una posesión diabólica, y que todavía a finales del siglo XVIII y comienzos del XIX caricaturistas como Gillray, Bunbury, Gruikshank, Grandville o Daumier expresaran la migraña, los dolores de gota o los provocados por cálculos renales representando en sus viñetas a diablillos y pequeños monstruos afanados en torturar al paciente.

Quien sufre tiende a percibir el dolor como si fuera un "ello". Explica a este respecto David Bakan que, si bien en circunstancias ordinarias el límite del yo coincide aproximadamente con el del cuerpo, siendo 
cuerpo y yo fenomenalmente una unidad en contraste con el medio ambiente, que es "otro", la presencia del dolor provoca un movimiento descentralizador que lo identifica con algo externo al cuerpo pero que a la vez sigue siendo interno al yo; en una palabra, un "ello". El dolor "no es parte del yo consciente, sino su antagonista: como algo que le ocurriese" (Bakan, 1979, p. 84). En el caso de los pacientes crónicos se han estudiado en detalle las cualidades perceptivas y conceptuales del mundo en el que estos viven su dolor. El universo del dolor crónico estaría caracterizado, según Michael Houseman (2005), por tres rasgos principales. El primero es un desarreglo de la percepción del tiempo y del espacio: si por un lado el paciente ve que no logra aprehender el tiempo, por otro en su estado de hipersensibilidad las fronteras del individuo se vuelven borrosas, produciéndose una confusión entre la parte y el todo del cuerpo. El segundo rasgo es la separación radical entre el que sufre y los demás, incrementada por la inadecuación del lenguaje frente al dolor. Por último, el mundo del dolor crónico reclama una explicación urgente, exige identificar las causas y motivos del sufrimiento. La confluencia de estos tres rasgos desembocaría para Houseman "en lo que representa tal vez la primera característica de la experiencia del dolor crónico, a saber una tendencia al desdoblamiento" (Houseman, 2005, p. 83). Una disociación que opera en varios registros: entre el yo y su existencia corporal, entre un yo dolorido y un yo sin dolor, entre un yo inconsciente y el yo consciente condenado a sufrir las penas. Por este motivo las personas que padecen dolor crónico ponen todo su empeño en entender las causas de su mal, tratan por todos los medios "de precisar la naturaleza de esta relación maléfica que los agobia: la que existe entre yo $y$ este ' $X$ ' que está en el origen del sufrimiento", de modo que a menudo "el dolor mismo se encuentra dotado de intencionalidad, convirtiéndose si no en un homúnculo sí al menos en un interlocutor eventual -un 'él' o un 'esto'- al que el individuo se somete o no, con el que lucha o negocia, etc." (2005, p. 85). El dolor crónico se caracteriza así por una configuración relacional que es a la vez más que una simple unidad y menos que una auténtica dualidad, está marcado "por un desdoblamiento inacabado e intrínsecamente inestable" (2005, p. 86). La persona que padece un dolor crónico se encuentra en una situación que recuerda singularmente al extraño caso que sufrió el Dr. Jekyll: no es ni uno, ni dual.

Así pues, el dolor sume al paciente en un estado de desdoblamiento del ser: es algo propio (me duele a mí y solo a mí) y a la vez es percibido como algo ajeno que se ha adherido a uno (eso no es mío). Es uno y es otro a un tiempo, como un doble. Al relatar recientemente sus Crónicas del dolor, Melanie Thernstrom no se sirve ya de la imagen decimonónica de unos diablillos para exponer sus síntomas sino de la de un acompañante que no se separa de uno mismo: "El dolor no era como un intruso violento que se abre paso a golpes, hace estragos y después se marcha. Se parecía más a un compañero de piso desagradable: un amigo íntimo y feo; una presencia amenazadora, sucia, que te distrae de tus asuntos y que, además, se niega a marcharse." (Thernstrom, 2012, p. 58). El dolor es ahora un doppelgänger, ese otro que camina a nuestro lado y que no nos abandona. De los minúsculos monstruos malvados revoloteando alrededor del paciente a este compañero indeseable que no quiere apartarse de uno, se evidencia un cambio significativo en la representación del dolor al que contribuyeron los avances médicos de la época moderna. Es preciso señalar a este respecto que si la disociación ocasionada en el individuo por el dolor puede haber cristalizado en la mente de numerosos artistas llevándolos a imaginar la figura moderna del doble, algún hecho determinante vinculado al padecimiento tuvo que atraer la atención de los poetas y los narradores decimonónicos para que fueran precisamente ellos, y no sus antecesores, quienes convirtieran al doppelgänger en un mito. $Y$ ese acontecimiento decisivo no fue otro que la posibilidad de anular o suprimir temporalmente el dolor que la ciencia había brindado a la humanidad en esos mismos años.

En una época en la que abundaron los conflictos sangrientos, en que en medio de la contienda los propios cirujanos tuvieron que librar sus propias cruentas batallas, operando y amputando en vivo a incontables soldados malheridos con la mayor prontitud, el descubrimiento de un procedimiento químico que permitiera suprimir la sensación de dolor durante las intervenciones fue saludado como una auténtica victoria de la humanidad sobre la naturaleza. La era de la cirugía moderna nació realmente cuando hacia 1850 la anestesia por éter o cloroformo fue reconocida como una forma efectiva de anular o bloquear el dolor del paciente. Este descubrimiento supuso para los hombres un cambio de tal magnitud que en la actualidad los estudiosos de la cultura del dolor no dudan en dividir la historia de la humanidad en dos periodos radicalmente distintos a partir de este hito (Cf. Morris, 1993, p. 70). Por primera vez el paciente no estaba ya confrontado al dilema de aguantar un sufrimiento insoportable o someterse a una operación aún más dolorosa para intentar librarse de su mal. 
Como toda revolución, el descubrimiento de la narcosis fue el resultado de una compleja y conflictiva gestación que duró más de cincuenta años. La historia del nacimiento de la anestesia es bien conocida y puede leerse en detalle en el monumental estudio de Thomas Dormandy: El peor de los males (2010) o en la fascinante Historia cultural del dolor de Javier Moscoso (2011). Aquí bastará recordar que a finales del siglo XVIII el interés por los gases atmosféricos condujo a los químicos a experimentar con éter, óxido nitroso y cloroformo, y aunque casualmente se observó que estos gases provocaban mareos, sobrexcitación y por último un profundo letargo, no se reparó en sus posibilidades para combatir el dolor. Como apunta Olivier Faure (2005, pp. 29-30), las investigaciones sobre el uso del éter no se dieron en las esferas médicas sino químicas, y los primeros experimentos se hicieron en Estados Unidos en el marco de espectáculos circenses extendiéndose desde aquí a las profesiones paramédicas, en particular a los dentistas que fueron los primeros en emplearlo para suprimir el proverbial dolor de muelas. Precisamente dos dentistas norteamericanos, H. Wells y W. G. Morton, así como un científico, Ch. Jackson, comparten la gloria de haber derrotado al dolor al demostrarse en 1846 la eficacia de los vapores del éter en una mesa de operaciones. En pocos meses, el método para dejar insensibles al dolor a los pacientes mediante un gas -bautizado por el cirujano Holmes con el nombre de anestesia (del prefijo privativo griego an y aiesthesis, sensación)- se extendió como la pólvora al continente europeo y fue recibido con entusiasmo por el cuerpo médico que al fin podía paliar el sufrimiento de los pacientes y dejar de oír sus gritos en la mesa de operaciones.

Pasada la exaltación inicial, advierte Javier Moscoso (2011, p. 166), la aparición de la anestesia tuvo no obstante que abrirse camino entre numerosas resistencias y críticas de orden corporativo, pero también religioso-moral. Un médico como James Young Simpson, el famoso cirujano escocés que en 1847 había descubierto las propiedades anestésicas del cloroformo y las había aprovechado para evitar a las mujeres los dolores del parto, tuvo que justificar su actuación recurriendo a la interpretación del Génesis. La aparición y aceptación de la anestesia solo fue posible cuando el espectáculo del sufrimiento se volvió intolerable y las masacres públicas fueron sustituidas por prácticas más "higiénicas" como la guillotina, cuando el individuo adquirió verdaderos derechos y empezó a disfrutar de una comodidad que le permitía prestar mayor atención a su cuerpo; cuando, en fin, dejó de contemplar la vida como un valle de lágrimas y fue reemplazando la idea cristiana del sacrificio por una felicidad de origen romántico que parecía estar cada vez más al alcance de la mano gracias a la prosperidad que acompañaba al progreso industrial ( $C f$. Corbin, 2005 , p. 279). Este cambio de mentalidad hizo que el individuo moderno comenzara a exigir que se aliviaran sus sufrimientos y contribuyó al éxito de los innovadores métodos para aliviar el dolor ( $C f$. Thernstrom, 2012, p. 125). A su vez el triunfo de la anestesia trajo consigo una transformación total de la existencia.

Si el dolor físico siempre había parecido consubstancial a la vida, acompañando al ser humano de la cuna a la tumba, a mediados del siglo XIX dejó de ser una necesidad absoluta y pudo concebirse como algo evitable. La irrupción de la anestesia en la práctica médica, señala en este sentido Le Breton (2006, p. 163), marca "las premisas de un cambio de mentalidades colectivas frente a un dolor menos asociado a lo ineluctable. Sufrir será percibido cada vez menos como un destino por víctimas convencidas con razón o sin ella de que la medicina tiene una respuesta antálgica a sus males." Ahora bien, si resulta posible eludir algo como el dolor ello significa en primer lugar que existe de forma objetiva. En este sentido, Thomas Dormandy aseguraba que "el hecho de que el dolor se pudiera suprimir era una prueba que demostraba su existencia" (2010, p. 413). Liberado parcialmente de sus antiguas representaciones teológicas, el dolor se convirtió a lo largo del siglo XIX en una función biológica que existía por derecho propio y podía ser controlada por los hombres. La capacidad para eliminar el dolor propició paradójicamente su objetivación. Antes de la anestesia el sufrimiento se confundía con la vida, no se reparaba en él de forma específica, era como una intensificación de otras sensaciones, pero desde el momento en que se pudo bloquear o anular, el dolor adquirió otra entidad, otra densidad, cobró cuerpo, aunque fuera un cuerpo fantasmagórico. Es entonces, una vez que la aparición de la anestesia completa el proceso de objetivación del dolor, ya iniciado con las intervenciones quirúrgicas bajo hipnosis o con el uso analgésico de opiáceos desde principios de siglo, cuando los artistas fijan una atención particular en el sufrimiento y desarrollan una sensibilidad manifiesta hacia él. El escritor decimonónico asume plenamente y lleva hasta sus últimas consecuencias la ideología romántica del sufrimiento artístico, no solo profundizando en esta estética del dolor y convirtiendo el acto de escritura en un parto, en una tortura e incluso, en el caso de un Flaubert, en un martirio, sino también expresando en la figura del doble la peculiar disociación que crea el dolor en el individuo. 
Al igual que a finales del siglo XX los avances en genética, popularizados con la clonación de la oveja Dolly, darían lugar a numerosas películas protagonizadas por dobles, el descubrimiento de la anestesia en el siglo anterior otorgó entidad y visibilidad a la singular naturaleza del dolor, propiciando de este modo que no pocos escritores convirtieran la antigua y legendaria figura del doble en el receptáculo donde hicieron cristalizar sus efectos disociativos. Nada de esto debería resultar sorprendente, pues durante ese siglo el dolor cobró más protagonismo en el ámbito social, político, científico y cultural del que había tenido jamás. La introducción de la técnica anestésica trajo consigo una reevaluación de la experiencia del dolor que pronto se propagó a los más diversos ámbitos de la sociedad. Antes de que la terapia de electrochoque se convirtiera en metáfora y procedimiento de la doctrina neoliberal (cf. Naomi Klein, 2007), la anestesia ya era una imagen muy extendida, hoy banal, de una sociedad indolora cuya conciencia permanece adormecida ante la insufrible realidad.

Susan Buck-Morss, analizando la modernidad como experiencia neurológica, ha mostrado de forma convincente que el uso de los anestésicos, descubierto en fiestas donde se inhalaba "gas de la risa" que producía sensaciones y visiones fascinantes antes de provocar sopor, surge precisamente en el mismo periodo en que la tecnología transforma la realidad en un narcótico, en una fantasmagoría. A la vez que la anestesia se generalizaba en los quirófanos, en las ciudades aparecían incesantemente nuevas formas fantasmagóricas como las galerías con sus novedosos escaparates, con sus panoramas y sus dioramas, se inauguraban exposiciones universales y se abrían grandes almacenes que tenían todos ellos "el efecto de anestesiar el organismo, no a través del adormecimiento, sino a través de una inundación de los sentidos" (Buck-Morss, 2005, p. 197); unos espectáculos de incipiente tecnología experimentados de forma colectiva, haciendo que todo el mundo percibiera el mismo mágico ambiente. Para Susan Buck-Morss la práctica anestésica documenta "una transformación en la percepción cuyas consecuencias sobrepasaron largamente la experiencia quirúrgica" (2005, p. 204): así como durante la operación el cirujano ya no tenía necesidad de reprimir su identificación con los dolores de su paciente, convertido ahora este en una masa inerte perfectamente manejable, la tecnología, la especialización laboral y la moderna racionalización produjeron un tecnocuerpo de la sociedad que parecía "tan insensible al dolor como el cuerpo individual bajo los efectos de la anestesia general, de tal modo que podía ejecutarse cualquier número de operaciones sobre el cuerpo social sin necesidad de preocuparse de que el paciente -la sociedad misma- profiriera gritos lastimosos y lamentos" (2005, p. 207).

En esta misma línea, Terry Eagleton, en un capítulo de La estética como ideología dedicado a la concepción estética de Marx, ha puesto de manifiesto que en los Manuscritos de economía y filosofía, redactados en 1844, es decir cuando el descubrimiento de la anestesia ya estaba en el aire, el joven filósofo alemán había tratado de reconsiderar y reconstruir la ética, la historia, la política y la racionalidad partiendo del cuerpo y haciendo que la sensibilidad fuera la base de toda ciencia. Al quedar ceñido el trabajador a sus necesidades más estrictas e instintivas, al reemplazar el capitalista sus propios sentidos físicos e intelectuales por el sentido único de tener, uno y otro, si bien por motivos bien distintos, se vieron condenados según Marx a una vida sensible alienada. Y es que bajo el capitalismo la plenitud corporal de los individuos se convierte en una simple parodia del cuerpo verdaderamente sensible. Si despoja al trabajador de sus sentidos al condenarlo a la miseria, el capitalista vive a su vez una sensualidad extrañada al forzar que sea el dinero el que haga aquello que él es incapaz de realizar, apropiándose del arte, de las curiosidades históricas, del poder político, etc. Su cuerpo permanece como anestesiado, carente de auténtica sensibilidad, dejando que sea el capital el que haga todas las cosas en su lugar, como si las realizara un doble, a semejanza de lo que le sucedería a Goliadkin, el desdichado protagonista de El doble de Dostoyevski. No es casual que sea precisamente esta la imagen que emplea Terry Eagleton para referir la forma vicaria de sensibilidad que proporciona el capital según el joven Marx:

El capital es un cuerpo fantasmal, un monstruoso Doppelgänger que acecha fuera mientras su señor duerme, y que consume mecánicamente los placeres a los que austeramente este último renuncia. Cuanto más abjura el capitalista de su propio placer, y, en lugar de esto, dedica sus esfuerzos a modelar esta especie de zombi alter ego, más satisfacciones de segunda mano es capaz de cosechar. Tanto el capitalista como el capital son imágenes de muertos vivientes, el uno animado aunque anestesiado, el otro inanimado aunque activo. (Eagleton, 2006, p. 270)

A este doble fantasmagórico que recorre el mundo mientras el cuerpo yace anestesiado, sin sentido(s), antepone Marx una concepción artística que pueda devolver a la vida su auténtica sensualidad. El significado que otorga a lo estético (del latín aesthetica, 
sensación) se aparta en este caso abiertamente del que poseía entre los filósofos desde Kant y que podría "describirse más exactamente como anestésico (anaesthetic)" (Eagleton, 2006, p. 265). Escindida entre un materialismo grosero y un idealismo caprichoso, la sociedad de clases parece haber anestesiado el cuerpo despojándolo de sus sentidos. Antítesis del fetichismo de la mercancía, la obra de arte es para Marx un fin en sí misma y su realización posee la virtud de restablecer una verdadera relación humana entre la cosa y el hombre. En este sentido solo se podrá vivir estéticamente cuando la necesidad material deje de constreñir los impulsos corporales, cuando desaparezca el monstruoso doppelgänger y recobre el cuerpo sus sensaciones. Para ello sería preciso abolir la propiedad privada y esto significaría "la emancipación plena de todos los sentidos y cualidades humanos" (Marx, 2013, p. 180). Los artistas más visionarios no tardarán asimismo en denunciar en sus obras el malestar que despierta en ellos una literatura que hace abstracción del cuerpo. Desde ópticas y poéticas muy distintas, autores como Lautréamont o Walt Whitman buscarán devolver al arte el nervio que había perdido, los sentidos y sensaciones que le habían sido arrebatados por una estética excesivamente racional. Y, según sus propias palabras, sorprendentemente similares a las de Marx, Rimbaud trabajará por su parte para "alcanzar lo desconocido mediante el desarreglo de todos los sentidos" (Rimbaud, 1999, p. 84). Una empresa estrechamente vinculada a la objetivación del dolor.

El siglo XIX, que ya avanzaba peligrosamente hacia su fin, llevaba decenios enredado en la oscura selva romántica de la subjetividad cuando Rimbaud, arropado tal vez por la osadía que concede la adolescencia, desbrozó de un golpe este enmarañado y espinoso terreno con su acerado verbo. Tantas excrecencias habían surgido en torno al Yo que ya no parecía posible determinar su verdadera naturaleza. Y entonces, en 1871, el joven poeta acertó a expresar, con precisión de cirujano, el extrañamiento de este Yo moderno en una sentencia que con el tiempo se haría justamente célebre: "Yo es otro" (Je est un autre). A pesar de tener cierta afinidad con ellas, esta novedosa fórmula difería sustancialmente de otras como aquella que Gérard de Nerval había escrito años antes al pie de uno de sus retratos, acaso para expresar la realidad oculta tras una litografía y descubrir a ese doble espectral que atormentaba sus noches y sus relatos: "Yo soy el otro" (Je suis l'autre). En el caso de Rimbaud, la escisión del sujeto no se manifiesta ya en la discordancia entre una imagen y el texto escrito a mano que la acompaña, sino en el tejido mismo del lenguaje. A simple vista su bisturí parece haber errado en su ejecución, cuando en realidad el Otro solo podía ser extraído del sujeto unitario operando un corte en la carnalidad del lenguaje, cometiendo una falta gramatical que hiciera visible en toda su crudeza la herida abierta que había que restañar. Victor Hugo se vanagloriaba de haber "puesto un gorro rojo al viejo diccionario" (1858, p. 32), un gorro frigio, revolucionario, que liberara al vocabulario de sus grilletes académicos; más radical aún que el viejo maestro, Rimbaud, simpatizante de la Comuna, se disponía a abrir la gramática y la propia poesía en canal. Un corte limpio y certero dejaba a la vista la falta de concordancia entre el sujeto y el verbo, entre el ser y el lenguaje, para que el sentido pudiera así derramarse en abundante hemorragia.

El dolor y sus efectos son el centro neurálgico de las dos famosas Cartas del Vidente donde en mayo de 1871 enunció Rimbaud su programa existencial y poético. En la primera, verdadero embrión de las ideas que desarrollaría en la segunda, empezaba aclarándole a su antiguo profesor Georges Izambard que si en aquel momento llevaba una vida disoluta no era por placer sino para cumplir con el destino que le correspondía en la sociedad. La nueva vida de Arthur Rimbaud, que entristecía tanto a su rigurosa madre, era un sacrificio que tenía que realizar para traer la buena nueva poética al mundo. De ahí la alusión fragmentaria, paródica y blasfema que hacía en esta misma carta al Stabat Mater, al pasaje del himno de la liturgia católica donde se canta el sufrimiento de la Virgen María cuando contempla a su hijo clavado en la cruz. "Stat mater dolorosa, dum pendet filius", escribía con ironía Rimbaud (1999, p. 83). Al igual que Cristo que, en palabras de Roberto Calasso, había representado el escándalo de "ser sacerdote y víctima al mismo tiempo" (1989, p. 149), haciendo visible de este modo el fundamento del sacrificio, a saber que "cada uno de nosotros es dos, y no uno" (1989, p. 137), Rimbaud, enganchado a sus actividades escandalosas, se sacrificaba a sí mismo en aras de la nueva poesía:

Por el momento, me encanallo lo más posible. ¿Por qué? Quiero ser poeta, y me esfuerzo en hacerme vidente: no lo entenderá usted en absoluto, y casi no sabría explicarle. Se trata de llegar a lo desconocido por el desarreglo de todos los sentidos. Los sufrimientos son enormes, pero hay que ser fuerte, haber nacido poeta, y me he reconocido poeta. No es en absoluto culpa mía. Es falso decir: Pienso [Je pense]. Habría que decir: Me piensan [On me pense]. Perdón por el juego de palabras.

YO es otro. iTanto peor para la madera que se descubre violín, y se burla de los inconscientes que ergotizan sobre aquello que ignoran por completo! (Rimbaud, 1999, p. 84). 
Al famoso Cogito ergo sum de Descartes parece Rimbaud anteponer una fórmula que disocia el supuesto origen de la identidad. Para este poeta que aspira a ser vidente, solo puede alcanzarse ese Yo desconocido, disociado, a costa de provocarse a sí mismo enormes sufrimientos. Aquí cuerpo y lenguaje se confunden, pues "el desarreglo de todos los sentidos" que debe sufrir el poeta ha de entenderse -valga la redundancia- en un doble sentido, como un trastorno voluntario de las más diversas sensaciones resultante de someter el cuerpo y la mente a variados experimentos, pero también, dada la acepción que tenía entonces la palabra dérèglement, como el conjunto de infracciones a las reglas de la poética que el escritor infligirá a su propia obra: por ejemplo, "Yo es otro" en lugar de "Yo soy otro". Así sucede en el resto de la carta, plagada de dobles sentidos que el propio Rimbaud se encarga de subrayar pidiéndole maliciosamente disculpas a Izambard por el juego de palabras. Pero ¿a qué juego de palabras se refiere el joven poeta?

Penser (pensar) y panser (curar, vendar) se pronuncian exactamente de la misma forma en francés. De hecho, en El hombre que ríe, una novela de Victor Hugo publicada dos años antes y que, como se verá, Rimbaud tenía en mente, el locuaz saltimbanqui Ursus juega con estos términos al presentarse ante su público como filósofo y médico: "En cuanto a mí, raciocinio y medicamento. Pienso [Je pense] y curo [je panse]. Chirurgus sum." (2002, p. 449). Así pues, cuando Rimbaud afirma que se debería decir On me pense (me piensan) al mismo tiempo está diciendo On me panse (me curan, me vendan una herida). Una auténtica alquimia del verbo. Allí donde me piensan, donde piensan en mi lugar, se oye el sonido reconfortante del apósito que aplican cuidadosamente a mis heridas para curarlas. Siguiendo a Ambroise Paré, Jean-Pierre Peter señalaba que "el uso de telas de dolor restaura, frente a la enfermedad y los sufrimientos, un orden del mundo en cuyo seno el hombre encuentra de nuevo la unidad de todas las cosas, y puede pues esperar el regreso de la suya y la promesa de eternidad" (1989, p. 81). En este sentido el pensamiento poético era asimismo para Rimbaud un vendaje capaz de reparar el daño, de reunir el Yo con el Ello, de aliviar y tal vez suprimir ese dolor que disocia al ser. La palabra poética, ambivalente y precisa a un tiempo, vendría a ser como una segunda piel, un tejido provisional que cubre y contribuye a que se regeneren los nuevos tejidos: un verdadero texto.

Todas estas ideas sobre la naturaleza de la poesía serían precisadas en la segunda carta. De nuevo afir- ma Rimbaud que "Yo es otro" y anuncia además que asiste a la eclosión de su propio pensamiento. Pero su concepción del vidente (voyant) está ahora bajo los auspicios de Prometeo, el Previsor (Prévoyant, en francés), pues, como le dice a Paul Demeny, "el poeta es verdaderamente ladrón de fuego", "un multiplicador de progreso" (Rimbaud, 1999, pp. 91-92). Maestro en el arte de la adivinación, Prometeo enseñó a los hombres a leer en las llamas los signos premonitorios hasta entonces insondables, robó el fuego sagrado a los dioses e inventó para ellos todos los saberes, las ciencias y las técnicas. El dolor inhumano que le causaba el águila al devorarle cada día el hígado es el precio que tuvo que pagar por ofrecer el progreso y la ciencia a la humanidad. Por ello, además de encarnar la rebeldía romántica, este promotor del progreso ha simbolizado tantas veces las penas y peligros que acarrea estar encadenado a la investigación. Rimbaud hace del poeta un vidente que acepta paradójicamente los enormes sufrimientos que entraña la experimentación científica. Es este un dolor que nada tiene de metafórico, pues el objeto sobre el que debe experimentar el poeta es su propia persona. El desarreglo de todos los sentidos es ahora "inmenso y razonado", una empresa que consiste en administrarse a sí mismo todas las formas de amor, de sufrimiento y de locura, "todos los venenos, para conservar de ellos únicamente las quintaesencias. Inefable tortura para la que necesita toda la fe, toda la fuerza sobrehumana, en la que entre todos se convierte en enfermo grave, gran criminal, gran maldito -iy supremo científico!-, pues llega a lo desconocido" (1999, pp. 88-89).

Enfermo y médico a la vez, el poeta de Rimbaud debe en primer lugar estudiarse a sí mismo, buscar su espíritu, inspeccionarlo y cultivarlo, es decir tratar "de hacer que el alma sea monstruosa: ja la manera de los comprachicos, vaya! Imagine un hombre implantándose verrugas en el rostro." (1999, p. 88). El pensamiento encuentra aquí su origen en el otro; no pienso, me piensan, porque el sentido de mis palabras emana del discurso ajeno. En efecto, los comprachicos a los que alude Rimbaud son los delincuentes que robaban niños para mutilarlos y hacer de ellos monstruos de feria que Victor Hugo había recreado en El hombre que ríe. El protagonista de esta novela, Gwinplaine, quien terminará convirtiéndose explícitamente en el Prometeo que se sacrifica por el pueblo, había sido sometido de niño a una operación quirúrgica que le había dejado en el rostro una risa permanente. Victor Hugo dedica abundantes páginas a describir esta "ciencia ingeniosa, probablemente oculta, que era a la cirugía lo que la alquimia es a la química" (Hugo, 
2002, p. 372), un arte siniestro que, con la ayuda de "los medios para dormir al paciente y suprimir el sufrimiento" a los que "hoy se les llama anestesia" (Hugo, $2002,377)$, buscaba "esculpir en plena carne humana" (Hugo, 2002, p. 71) hasta lograr crear sobre el rostro original una máscara carnal. Gwinplaine no podía saber cuál era su verdadero rostro: "Habían puesto sobre él un falso sí mismo. Tenía por rostro una desaparición” (Hugo, 2002, p. 380). Nadie sabía mejor que él que "Yo es otro". El poeta que imagina Rimbaud es asimismo un hombre que ríe pero que ha optado por esculpir él mismo su sonrisa. Ya no es solo víctima, ejerce también de oficiante de un rito científico. Es sujeto y objeto de su investigación, como un hombre de ciencia que experimenta con su propia persona, como un artista contemporáneo que utiliza su cuerpo a modo de lienzo o de materia moldeable. El experimento, que es "un sacrificio del cual ha sido eliminada la culpa" (Calasso, 1989, p. 139), es el medio del que se vale para alcanzar la sabiduría y hacerse vidente. Pero, como señala Amelia Gamoneda en un artículo esencial sobre Rimbaud, esta sabiduría "se cultiva en un laboratorio digno de Mister Hyde, donde se desvela la cara oculta y 'otra' del sujeto." (2008, p. 51). Rimbaud, al igual que unos años más tarde el doctor Jekyll, se sacrifica a sí mismo administrándose unos fármacos peligrosos que trastornan sus sentidos y le permiten observar la otra naturaleza de su alma.

La anestesia tardó mucho tiempo en librarse de su halo siniestro. Una de las razones frecuentemente aducidas entonces para oponerse al uso del cloroformo era que resultaba repugnante e incluso indecente operar a alguien que estuviera inconsciente. En efecto, a la vez que eliminaba el dolor, la anestesia anulaba los sentidos y suprimía la consciencia del paciente, y se temía, especialmente en el caso de las mujeres, que desapareciera asimismo su moralidad. Por ello, James Young Simpson insistía en que jamás había presenciado ninguna palabra o acción indecentes en una paciente anestesiada con cloroformo (Cf. Moscoso, 2011, pp. 148-151). Lo que motivaba unas reticencias que hoy parecerían absurdas era en realidad el miedo del individuo a perder la unidad de su ser, un temor que quedaba patente en tantas obras literarias de la época.

Ya en los poemas en los que se ensalzaban las bondades del progreso, como en Los cantos modernos de Maxime du Camp, podía observarse el poder de abducción que se atribuía a la anestesia: “iEscuchad! Es el cloroformo / Que dice: "iHe matado el dolor; / Mientras el instrumento deforme / Corta las carnes con lentitud, / yo tomo el espíritu y lo traslado / Lejos de todo contacto doloroso, / Y me lo llevo como un sueño / Al país de los azules ensueños!" (du Camp, 1855, p. 267). No siempre tal rapto del espíritu resultaba sin embargo tan encantador. En efecto, poco tiempo después, el protagonista de Los cantos de Maldoror daría a este invento un uso mucho menos angelical al aprovechar la inconsciencia de una joven para cortarle un brazo "durante la noche, gracias al cloroformo" (Lautréamont, 2009, p. 100). Maldoror, ese monstruo que se encuentra bello al contemplar en un espejo la dualidad de la que está compuesto $(2009$, p. 238) y que maneja el escalpelo con la habilidad de un cirujano y el sadismo de un psicópata ( $C f$. González, 2014), advierte con su acción que la anestesia puede suponer la amputación de una parte de sí mismo, del cuerpo o del alma. Así lo entendía también Balzac, según el testimonio de Jules Claretie, cuando decía que "aunque me cortasen una pierna, jamás me dejaría cloroformar. No quisiera nunca abdicar de mi yo." (Claretie, 1881, p. 381). Al suprimir la consciencia, el cloroformo parece atentar contra la unidad y la moralidad del invididuo. Stevenson es el novelista que con más clarividencia acabaría de materializar en el doble estos efectos disociativos del cloroformo que tanto inquietaban al resto de escritores.

Bajo el influjo de los elixires del diablo el monstruo que habita nuestro inconsciente suplanta al hombre virtuoso que creíamos ser. Ni siquiera un médico puede entonces evitar que emerja de las profundidades su otra naturaleza siniestra. Robert Louis Stevenson expresó a la perfección en El extraño caso del Dr. Jekyll y Mr. Hyde los temores que ocasionaba el uso de la anestesia (Cf. González, 2006). Nadie estaba en realidad mejor situado que él para conocer sus efectos sobre las personas pues, como recuerda Nicholas Rankin, los Stevenson vivían en Edimburgo, en Queen Street Gardens, justo enfrente de la casa de James Young Simpson, "y había amistad entre ambas familias. Robert Louis Stevenson había conocido a Sir James antes de que muriera en 1870 , y hasta 1876 , el hijo y heredero del médico, Sir Walter Simpson, Bart, fue su compañero de viaje" (Rankin, 2010, p. 89). El novelista conocía de primera mano el relato del descubrimiento del cloroformo, aquel famoso episodio de la historia de la ciencia en el que durante una velada Simpson y dos de sus colegas habían probado este nuevo producto, sufriendo en el acto una verdadera metamorfosis en su comportamiento habitual antes de caer en un profundo sopor (Cf. Dormandy, 2010, p. 339). Esta experiencia de Simpson fue de hecho "la fuente de inspiración del doctor Henry Jekyll, triste- 
mente famoso por experimentar con su propio cuerpo." (Rankin, 2010, p. 89). En el misterioso fármaco del Dr. Jekyll todavía podía reconocerse el aroma del cloroformo al que durante años se había atribuido la propiedad de disociar el alma del cuerpo. Porque no pienso, sino que me piensan, me curan las heridas gracias a esos vapores analgésicos de donde emana y cobra forma ese otro que hay en mí.

\section{BIBLIOGRAFÍA}

Arnaud, C. (2006). Qui dit je en nous? Paris: Grasset.

Bakan, D. (1979). Enfermedad, dolor, sacrificio. Hacia una psicología del sufrimiento. México: Fondo de Cultura Económica.

Breton, D. Le (1995). Anthropologie de la douleur. Paris: Éditions Métailié.

Buck-Morss, S. (2005). Estética y anestésica: una reconsideración del ensayo sobre la obra de arte. En: Buck-Morss, S. Walter Benjamin, escritor revolucionario. Buenos Aires: Interzona, pp. 169-221.

Calasso, R. (1989). La ruina de Kasch. BarceIona: Editorial Anagrama.

Camp, M. du (1855). Les chants modernes. Paris: Lévy Frères.

Claretie, J. (1881). La vie à Paris. 1881. Paris: Victor Havard Editeur.

Corbin, A. (2005). Douleurs, souffrances et misères du corps. En: Corbin, A. (ed.). Histoire du corps 2. De la Révolution à la Grande Guerre. Paris: Editions du Seuil, pp. 221-281.

Dormandy, Th. (2010). El peor de los males. La lucha contra el dolor a lo largo de la historia. Madrid: Antonio Machado.

Eagleton, T. (2006). La estética como ideología. Madrid: Editorial Trotta.
Faure, O. (2005). Le regard des médecins. En Corbin, A. (ed.). Histoire du corps 2. De la Révolution à la Grande Guerre. Paris: Editions du Seuil, pp. 15-52.

Gamoneda, A. (2008). Rimbaud: Videncia y evidencia. En: Casado, M. y Collot, M. (eds.) Rimbaud, el otro. Madrid: Editorial Complutense, pp. 47-58.

González, F. (2006): El dolor y su doble. Metáforas del tormento de la escritura en el cine y la literatura. En: Domínguez, V. (ed.). El dolor. Los nervios culturales del sufrimiento. Oviedo: Festival Internacional de Cine de Gijón/ Ediuno, pp. 69-99.

González, F. (2014). Coser y cantar: la mesa de disección geométrica de Lautréamont. Signa. Revista Española de Semiótica, 23, pp. 143-174.

Houseman, M. (2005). Quelques configurations relationnelles de la douleur. En: Héritier, F. (ed.) De la violence II. Paris: Odile Jacob Editions, pp. 77-112.

Hugo, V. (1858). Les Contemplations. Paris: Hachette.

Hugo, V. (2002). L'homme qui rit. Paris: Librairie Générale Française.
Klein, N. (2007). La doctrina del shock. El auge del capitalismo del desastre. Barcelona: Ediciones Paidós.

Lautréamont, Conde de (2009). CEuvres complètes. Paris: Gallimard.

Marx, K. (2013). Manuscritos de economía y filosofía. Madrid: Alianza Editorial.

Morris, D. (1993). La cultura del dolor. Santiago de Chile: Editorial Andrés Bello.

Moscoso, J. (2011). Historia cultural del dolor. Madrid: Editorial Taurus.

Pélicier, Y. (1995). La problématique du double. En: Troubetzckoy, W. (ed.) La figure du double. Paris: Didier, pp. 125-139.

Peter, J.-P. (1989). Linges de souffrance, texture de chair: problèmes et stratégies du pansement. Ethnologie française, 19 (1), pp. 7-82.

Rankin, N. (2010). Robert Louis Stevenson. De Escocia a los Mares del Sur. Madrid: Siglo XXI.

Rimbaud, A. (1999). Poésies. Une saison en enfer. Illuminations. Paris: Gallimard.

Thernstrom, M. (2012). Las crónicas del dolor. Barcelona: Editorial Anagrama. 